\title{
Profissionalização dos professores: conhecimentos, saberes e competências necessários à docência
}

\section{Professionalization of professors: knowledge, wisdom and necessary abilities to teaching}

\author{
Roberto Valdés Puentes* \\ Orlando Fernández Aquino** \\ Armindo Quillici Neto***
}

\begin{abstract}
RESUMO
Objetivamos analisar diferentes classificações e tipologias sobre os conhecimentos, saberes e competências necessários ao exercício da docência. Os onze estudos levantados representam uma parte modesta das pesquisas realizadas nas duas últimas décadas. Ainda assim, foi possível, a partir deles, chegar a quatro conclusões; primeiro, que é enorme a variedade de autores que têm pretendido ordenar a pluralidade, composição e heterogeneidade dos saberes profissionais dos professores; segundo, que as próprias classificações e tipologias elaboradas, como resultado desses estudos, são tão plurais, diversas e heterogêneas como seu objeto de análise, o que torna impossível uma comparação entre elas; terceiro, que a proliferação de classificações e tipologias em lugar de melhorar a compreensão dos saberes por elas estudados, aumentou sua complexidade e os tornaram menos inteligíveis; quarto, que apesar da diversidade de enfoques ser plural, diversa e heterogênea, o significado conceitual é quase o mesmo nos onze autores estudados.

Palavras-chave: profissionalização dos professores; docência; conhecimento.

* Doutor em Educação (Unimep). Professor Adjunto da Faculdade de Educação da Universidade Federal de Uberlândia - FACED/UFU. E-mail: robertopuentes@faced.ufu.br

** Doutor em Ciências Pedagógicas (ISP/Villa Clara, Cuba). Docente do Curso de Especialização em Língua e Literaturas Espanhola e Hispano-americana do Instituto de Letras e Linguísticas (UFU).E-mail: ofaquino@gmail.com

*** Doutor em Educação (Unicamp). Professor Adjunto das Faculdades Integradas do Pontal da Universidade Federal de Uberlândia - FACIP/UFU. E-mail: armindoqn@terra.com.br
\end{abstract}




\begin{abstract}
We have as a goal to analyze different classifications and types of knowledge, wisdom and necessary abilities to the exercise of teaching. The eleven raised studies represent a modest part of the research made in the two last decades. Still thus, it was possible, get to four conclusions about them; first, that there is a variety of authors who have intended to command the plurality, composition and heterogeneity of professional knowledge of the professors; secondly, that the classifications and types of abilities elaborated, as a result of these studies, are as plural, diverse and heterogeneous as their object of analysis, what makes impossible a comparison between them; third, the proliferation of classifications and types in place of improving the understanding of knowledge studied by them, it increased their complexity and made them less intelligible; fourth, in spite of being plural, diverse and heterogeneous, the variety of approaches had the same meaning or almost the same for the 11 authors studied.
\end{abstract}

Keywords: professionalization of professors; teaching; knowledge.

\title{
Introdução
}

As pesquisas sobre profissionalização docente cresceram expressivamente nos últimos vinte anos. Tal aumento começou a ser experimentado a partir da década de 1980, associado ao movimento reformista da educação básica que se empreendera nos Estados Unidos, Canadá, Austrália e Inglaterra, inicialmente; na Europa Francófona (Bélgica, França, Suíça), posteriormente; e na América Latina, a partir da década de 1990 (TARDIF, 2000; NUNES, 2001).

Segundo Gauthier et al. (1998), nas últimas duas décadas do século XX a educação tem sido acusada, com insistência e vigor, de não cumprir convenientemente seu papel. Essa intimação além de estender-se à escola, atingiu, também, e, especialmente, os professores, considerados os principais responsáveis pela crise dada à falta de saberes necessários ao exercício da docência. De maneira que, além da busca pela melhoria da qualidade da educação, as críticas e propostas decorrentes dos movimentos de reforma têm por objetivo a reivindicação do status profissional para os profissionais da educação (ALMEIDA; BIAJONE, 2005).

No caso do Brasil, especificamente, destacam-se as abordagens sobre formação de professores realizadas no âmbito das linhas de pesquisa dos programas de pós-graduação (stricto sensu), demonstrando o grande interesse que essa 
temática tem suscitado entre os pesquisadores da área, bem como dos Grupos de Trabalho da Associação Nacional de Pós-Graduação e Pesquisa em Educação - ANPEd - e dos encontros regionais de pesquisa (BITTAR, 2005). Para que se tenha uma ideia, no período de 1997-2000, os estudos sobre formação de professores que foram realizados, associados aos Programas de Pós-Graduação, cresceram $22 \%$ em relação ao conjunto da produção da área de educação e $89 \%$ em relação ao período 1990-1996 (GARRIDO; BRZEZINSKI, 2005).

Os assuntos mais discutidos pela literatura científica consultada (PUENTES, 2005), dentro da temática da reivindicação do status profissional dos professores, têm sido: 1) a conceitualização da profissionalização docente; 2) os aspectos integrantes do processo de profissionalização; 3) as etapas na profissionalização; 4) as condições indispensáveis ou necessárias para a profissionalização; 5) os saberes, conhecimentos, competências e desempenhos considerados necessários à profissão; 6) os problemas que afetam a profissionalização, além de outros.

Os saberes, conhecimentos e competências necessários à profissão docente, especificamente, ocupam lugar de destaque nessa lista. Apoiados na premissa de que existe um conjunto de conhecimento base (Knowledge base) para o ensino, os teóricos afirmavam, e ainda afirmam, que é possível convalidar esse corpus de saberes com a intenção de melhorar a formação dos professores. Cunha (2004, p. 37), por sua vez, tem enfatizado que "assumir a perspectiva de que a docência se estrutura sobre saberes próprios, intrínsecos à sua natureza e objetivos, é reconhecer uma condição profissional para a atividade do professor".

$\mathrm{Na}$ época de 1980, muitos pesquisadores destinaram-se ao estudo e a sistematização desses saberes que estão na base da profissionalização da docência. Segundo Borges (2001, p. 1), "pelo menos nos últimos 20 anos [...], a partir de concepções e orientações variadas, milhares de pesquisas sobre ensino, os docentes e seus saberes têm sido produzidas [...] E a cada ano, é publicado um número extraordinário de obras e artigos sobre esse tema, em diversos lugares no mundo todo".

O propósito do presente trabalho é estudar as tipologias e classificações sobre os conhecimentos, os saberes e as competências dos docentes, surgidas dessas pesquisas a que faz referência Borges (2001). Ainda assim, não se pretende esgotar aqui todo esse universo de pesquisa, o que seria impossível por razões de espaço. Nesse sentido, foram selecionados apenas onze trabalhos que fornecem uma visão generalizada sobre os saberes docentes e permitem colocar em evidência a evolução experimentada pelo tema. $\mathrm{O}$ critério de seleção responde a três princípios muito simples: 1- à disponibilidade dos trabalhos em seu formato impresso ou digital; 2- à abrangência dos mesmos, de maneira que resultassem representativos do ponto de vista geográfico (Europa, América do 
Norte, América Latina, incluindo o Brasil), temático (saberes, competências, conhecimentos) e temporal (desde suas origens na década de 1980 até atualidade); 3- ao cuidado em incluir, preferencialmente, trabalhos pouco conhecidos no Brasil ou que ainda não dispõem de versão em língua portuguesa (SHULMAN, 1987; GARCÍA, 1992; BRASLAVSKY, 1999; ZABALZA, 2006).

Procede-se da seguinte maneira: primeiro, apresentam-se os estudos selecionados, agrupados em três famílias diferentes: 1) conhecimentos necessários à docência; 2) saberes necessários à docência; 3) competências necessárias à docência. Em segundo lugar, busca-se apreender como esses trabalhos definem (quando é feito) os saberes, os conhecimentos e/ou as competências docentes numa perspectiva conceitual e tipológica. Em terceiro lugar, trata-se de refletir a respeito das tipologias e classificações, situando suas contribuições e o nível de desenvolvimento alcançado.

\section{As tipologias e classificações do objeto de estudo}

As pesquisas que são estudadas correspondem a Shulman (1987), García (1992), Freire (1996), Gauthier et al. (1998), Braslavsky (1999), Pimenta (1998, 2002), Masetto (1998), Perrenoud (2000), Tardif(2003), Cunha (2004) e Zabalza (2006), respectivamente.

No Brasil, a introdução da temática dos saberes da docência deu-se, inicialmente, pelas obras de Tardif(1991), de Gauthier et al. (1998) e de Shulman (1987) e, posteriormente, pela divulgação dos trabalhos de autores brasileiros (FREIRE, 1996; MASETTO, 1998; PIMENTA, 1998, 2002; CUNHA, 2004) e de europeus (PERRENOUD, 2000). Pelo contrário, os estudos de García (1992), Braslavsky (1999) e Zabalza (2006), não têm circulado no país, pelo menos, na língua portuguesa.

\section{Conhecimentos necessários à docência}

Dos onze estudos que são objeto de análise, apenas dois utilizam o termo "conhecimento", ao fazer referência àquilo que os professores deveriam compreender sobre a docência para favorecer um processo de ensino-aprendizagem eficiente. Eles são a Base de conhecimentos da docência de Shulman (1986) e o Conhecimento Profissional dos Professores de García (1992).

Nem em Shulman e nem em García observa-se uma clara preocupação por definir o termo "conhecimento" da docência, mas o conceito está implícito 
nos dois trabalhos, de maneira muito similar em ambos. Para Shulman (2005, p. 5), o "conhecimento" sobre a "docência" é aquilo que os "professores deveriam saber, fazer, compreender ou professar para converter o ensino em algo mais que uma forma de trabalho individual e para que seja considerada entre as profissões prestigiadas"; enquanto que para García (1992, p. 1), é o conjunto de "conhecimentos, destrezas, atitudes, disposições que deverá possuir um professor do ensino".

Shulman é um dos autores que mais tem contribuído para o progressivo fortalecimento do campo educacional dos saberes docentes. Em The Knowledge Growth in Teaching [Desenvolvimento do conhecimento no ensino], dirigida em Stanford, a partir de 1986, estabeleceu os fundamentos para a reforma da educação sobre uma ideia do ensino que enfatiza a compreensão, a transformação e a reflexão. Nela, se expõe um argumento relativo ao conteúdo, o caráter e as fontes de um conhecimento necessário para o ensino como resposta à pergunta acerca da base intelectual, prática e normativa adequada para a profissionalização da docência.

Um ano depois, Shulman (1987) discursa sobre quais qualidades e profundidade de compressão, habilidades e capacidades, traços e sensibilidades transformam uma pessoa em um professor competente e define isto como "conhecimento base" para a docência. Segundo ele, são sete, no mínimo, as categorias da base de conhecimentos do professor: 1) conhecimento do conteúdo; 2) conhecimento pedagógico (conhecimento didático geral), tendo em conta, especialmente, aqueles princípios e estratégias gerais de condução e organização da aula, que transcendem o âmbito da disciplina; 3) conhecimento do currículum, considerado como um especial domínio dos materiais e os programas que servem como "ferramentas para o ofício" do docente; 4) conhecimento dos alunos $e$ da aprendizagem; 5) conhecimento dos contextos educativos, que abarca desde o funcionamento do grupo ou da aula, a gestão e financiamento dos distritos escolares, até o caráter das comunidades e culturas; 6) conhecimento didático do conteúdo, destinado a essa especial amalgama entre matéria e pedagogia, que constitui uma esfera exclusiva dos professores, sua própria forma particular de compreensão profissional; 7) conhecimento dos objetivos, as finalidades e os valores educativos, e de seus fundamentos filosóficos e históricos (SHULMAN, 2005, p. 11).

Na opinião do autor norte-americano, as pesquisas didáticas, até a década de 1980, tinham prestado pouca atenção a aspectos associados às metodologias (o como ensinar?) e às dificuldades do ensino de cada disciplina ou áreas que compõem o currículo escolar. Por esse motivo, a maior parte de suas discussões posteriores versaram em torno do que ele mesmo chamara de "conhecimento didático do conteúdo" (pedagogical knowledge matter). Ninguém antes que ele 
chegou a considerar a existência, no professor, de um conhecimento didático do conteúdo, diferenciado do conhecimento próprio do conteúdo.

O estudo de García (1992), sobre os componentes do conhecimento profissional dos professores, aparece num momento no qual se assiste às universidades espanholas envolvidas na elaboração de novos planos de estudo para a formação de professores de educação infantil, primária (fundamental) e secundária (média). O texto aborda, especificamente, o problema relacionado com o tipo de especialização didática que deveriam receber os aspirantes a professor do ensino médio; isto é, quais são os conhecimentos, habilidade, atitudes, disposições que deve possuir um professor do ensino secundário (médio).

O próprio título do trabalho revela sua proximidade temática com as abordagens realizadas por Shulman. García, a partir da análise dos estudos, não só de Shulman (1986, 1987, 1988, 1992), mas também dos colaboradores de Shulman, eleva a um patamar superior os estudos sobre o "conhecimento didático do conteúdo". Na ocasião, estabelece os componentes que deveriam integrar os conhecimentos profissionais dos professores. A saber: 1) conhecimento pedagógico geral, concebido como os conhecimentos, crenças e habilidades que os professores possuem e que estão relacionados com o ensino, com a aprendizagem, os alunos; assim como sobre os princípios gerais do ensino, tempo de aprendizagem acadêmico, tempo de espera, ensino em pequenos grupos, gestão da classe etc. (GARCÍA 1992, p. 5); 2) conhecimento do conteúdo, associado aos conhecimentos que os professores deverão possuir da matéria que ensinam (GARCÍA, 1992, p. 5); 3) conhecimento do contexto, que faz referência ao lugar onde se ensina, assim como a quem se ensina (GARCÍA, 1992, p. 6); 4) conhecimento didático do conteúdo, um tipo especial de conhecimento.

García (1992, p. 3), ao tomar como pressuposto o fato de que "é preciso prestar maior atenção - conceitual e empírica - à forma em que os professores 'transformam' o conhecimento que possuem da matéria em conhecimento 'ensinável' e compreensível para os alunos" e ao dedicar a maior parte do texto à abordagem deste último tipo de conhecimento (conhecimento didático do conteúdo), faz com que aquela proximidade sua com a obra de Shulman, de que já se falou, passe a ser, além de temática, também teórica e metodológica.

\section{Saberes necessários à docência}

O grupo de autores que utiliza o termo "saberes" para referir-se à ação de conhecer, compreender e saber-fazer associado à docência é mais numeroso e popular, no Brasil, que qualquer outro dos grupos estudados. O mesmo está integrado por Freire (1996), Pimenta (1998, 2002), Gauthier et al. (1998), Tardif (2003) e Cunha (2004). Deles, apenas Tardif parece ter uma preocupação explí- 
cita por definir o que entende por "saberes". Gauthier et al. e Cunha preferem retomar a conceitualização dada pelo autor canadense.

O estudo de Freire (1996) tem, como temática central, o aspecto da formação docente ao lado da reflexão sobre a prática educativo-progressiva em favor da autonomia dos educadores. Segundo o pensador, os saberes indispensáveis à prática docente de educadores críticos, progressistas, devem ser conteúdos obrigatórios à organização programática da formação docente e podem ser enumerados de um a dez: 1) ensinar não é transferir conhecimento, mas criar as possibilidades para sua produção ou a sua construção, uma vez que inexiste validade no ensino do qual não resulta um aprendizado; 2) ensinar exige rigorosidade metódica, na medida em que é preciso reforçar no aluno sua capacidade crítica, sua curiosidade, sua insubmissão e o rigor metódico com que deve aproximar-se dos objetos cognoscíveis; 3) ensinar exige pesquisa, no sentido da busca contínua, da indagação, da reprocura, da constatação e da intervenção; 4) ensinar exige respeito aos saberes dos educandos, toda vez que é necessário respeitar os conhecimentos socialmente construídos pelos alunos na prática comunitária e discutir com eles a razão de ser de alguns desses saberes em relação ao ensino dos conteúdos; 5) ensinar exige criticidade, vista como curiosidade, inquietação e rigor na aproximação ao objeto cognoscível; 6) ensinar exige estética e ética, no sentido que o rigor da crítica não pode ir à contramão de uma rigorosa formação ética e estética, pois, quando se respeita a natureza do ser humano, o ensino do conteúdo não pode ficar alheio à formação moral do educando; 7) ensinar exige a corporeificação das palavras pelo exemplo, na medida que pensar certo é fazer certo; 8) ensinar exige risco, aceitação do novo e rejeição a qualquer forma de discriminação; 9) ensinar exige reflexão crítica sobre a prática, pois na formação permanente dos professores, o momento fundamental é o da reflexão crítica sobre a prática; 10) ensinar exige o reconhecimento e a assunção da identidade cultural.

Já a classificação de Pimenta (1998), se dá no mesmo contexto de efervescência nacional, onde a problemática dos saberes dos professores é evidente e está em discussão. Segundo a autora, são três os saberes necessários ao exercício da docência, isto é: 1) saberes da experiência, que dizem do modo como nos apropriamos do ser professor em nossa vida; 2) saberes da área do conhecimento, conhecimentos especíicos, conhecimentos científicos, pois ninguém ensina o que não sabe e; 3) saberes pedagógicos, saber pedagógico e saber didático, isto é, a relação professor-aluno, a importância da motivação e do interesse dos alunos no processo de aprendizagem, as técnicas ativas de ensinar etc.

Apenas quatro anos depois, Pimenta (2002, p. 71), com a colaboração de Anastasiou, reformula sua tipologia e classificação inicial, elevando de três para quatro o número de saberes necessários à docência. Mantém inalterável, na forma 
e no conteúdo: os saberes da experiência e os saberes da área do conhecimento, e divide os saberes pedagógicos em: 1) saberes pedagógicos propriamente ditos (responsáveis por pensar o ensino como uma prática educativa, com diferentes e diversas direções de sentido na formação do humano); e 2) saberes didáticos (responsáveis pela articulação da teoria da educação e da teoria de ensino para ensinar nas situações contextualizadas).

Mais conhecido internacionalmente que o trabalho anterior, o reservatório de saberes, associado à profissionalização da docência de Gauthier et. al. (1998), também está vinculado aos estudos que abordam a natureza dos saberes subjacentes ao ato de ensinar; isto é, o conjunto de conhecimentos, competências e habilidades que servem de alicerce à prática do magistério e que poderão, eventualmente, ser incorporados aos programas de formação de professores.

Gauthier et al. (1998), no esforço por superar um ofício feito sem saberes e saberes sem ofício, apresentam uma outra visão do ensino, que parte da concepção segundo a qual seis saberes devem ser mobilizados pelos professores para o exercício da docência. São eles: 1) saber disciplinar, referente ao conhecimento do conteúdo a ser ensinado; 2) saber curricular, referente à transformação dos saberes produzidos pela ciência num corpus que será ensinado nos programas escolares; 3) saber das ciências da educação, relacionado com o conjunto de conhecimentos profissionais adquiridos que não estão diretamente vinculados com a ação de ensinar; 4) saber da tradição pedagógica, relativo ao saber dar aula que se tem antes da formação docente, adaptado e modificado mais tarde pelo saber experiencial e, principalmente, validado ou não pelo saber da ação pedagógica; 5) saber experiencial, referente aos julgamentos privados que o professor elabora com base na sua própria experiência, elaborando, ao longo do tempo, uma espécie de jurisprudência; 6) saber da ação pedagógica, o saber experiencial dos professores a partir do momento em que se torna público e que é testado por meio das pesquisas realizadas em sala de aula.

A contribuição mais importante de Gauthier et al. (1998) está, precisamente, no alongamento do campo teórico desse último saber, ou seja, o da ação pedagógica, até o momento, considerado como o menos desenvolvido no reservatório de saberes do professor e, também, contraditoriamente, o mais necessário à profissionalização do ensino. Segundo afirmam Gauthier et al. (1998, 34), "não poderá haver profissionalização do ensino enquanto esse tipo de saber não for mais explicitado, visto que os saberes da ação pedagógica constituem um dos fundamentos da identidade profissional do professor".

A obra de Tardif, como a de Gauthier et al. (1998), tem sido amplamente divulgada no Brasil desde princípios da década de 1990. Em um texto inicial, escrito em parceria com Lessard e Lahaye (1991), propõe uma solução para a questão do "pluralismo epistemológico" dos saberes do professor, e estabelece e 
descreve, muito sucintamente, uma nova classificação e tipologia, integrada por quatro saberes diferentes: 1) da formação profissional (da ciência da educação e da ideologia pedagógica), referente ao conjunto de saberes transmitidos pelas instituições de formação de professores; 2) disciplinares, relacionados com os saberes dos diversos campos do conhecimento, os saberes de que dispõe a nossa sociedade, tais como se encontram hoje integrados nas universidades, sob a forma de disciplinas (por exemplo, matemática, literatura, história, etc.); 3) curriculares, associado aos discursos, objetivos, conteúdos e métodos, a partir dos quais a instituição escolar categoriza e apresenta os saberes sociais por ela definidos e selecionados como modelos de cultura erudita e de formação para a cultura erudita; 4) experienciais, vinculados ou baseados no trabalho cotidiano do professor e no conhecimento de seu meio, os quais brotam da experiência e são por ela validados.

Nove anos depois, Raymond (2000) retoma o assunto das classificações e tipologias e propõe um outro modelo tipológico para identificar e classificar os saberes dos professores. A tipologia em questão está integrada por cinco saberes: 1) pessoais dos professores, adquiridos na família, no ambiente de vida, pela educação no sentido lato e integrado no trabalho docente pela história de vida e pela socialização primária; 2) provenientes da formação escolar anterior, adquiridos na escola primária e secundária e nos estudos pós-secundários não especializados, e integrados pela formação e pela socialização pré-profissional; 3) provenientes da formação profissional para o magistério, adquiridos nos estabelecimentos de formação de professores, nos estágios, nos cursos de reciclagem e integrados pela formação e pela socialização profissionais nas instituições de formação de professores; 4) provenientes dos programas $e$ livros didáticos usados no trabalho, adquiridos na utilização das ferramentas dos professores: programas, livros didáticos, cadernos de exercício, fichas, e integrados pela utilização de ferramentas de trabalho e sua adaptação às tarefas; 5) provenientes de sua própria experiência na profissão, adquiridos na prática do ofício na escola e na sala de aula e integrados pela prática do trabalho e pela socialização profissional.

Cunha (2004), inspirada na definição de Tardif (2003) e em toda sua obra, propõe uma classificação dos saberes dos professores que se relaciona, especificamente, com o campo da didática. O texto em questão tem por objetivo, na reflexão analítica dos saberes docentes, identificar a natureza desses saberes e em que medida, aqueles ligados à didática, são fundamentais para a estruturação profissional do professor, devendo constituir o construto de sua formação inicial e/ou continuada.

A autora, obedecendo a um critério específico de agrupamento, estabelece cinco núcleos privilegiados de saberes que se articulam e definem dependências 
recíprocas. A saber: 1) os relacionados com o contexto da prática pedagógica, vinculados ao saber identificar as teias sociais e culturais que definem o espaço em que os processos de ensinar e aprender acontecem e como se dá a interrelação entre elas (conhecimento da escola, a história das disciplinas escolares, das políticas que envolvem a escola etc.); 2) os relacionados com a ambiência de aprendizagem, vinculados às habilidades de incentivo à curiosidade dos alunos e o conhecimento das condições de aprendizagem e das múltiplas possibilidades que articulam conhecimento e prática social); 3) os relacionados com o contexto sócio-histórico dos alunos, associados às habilidades de leitura da condição cultural e social dos estudantes ao estímulo de suas capacidades discursivas e de recomposição de suas memórias educativas; 4) os relacionados com o planejamento das atividades de ensino, vinculados às habilidades de delinear objetivos de aprendizagem, métodos e propostas de desenvolvimento de uma prática efetiva (saber dimensionar o tempo disponível, relacionando-o à condição dos alunos e às metas de aprendizagem); 5) os relacionados com a condução da aula nas suas múltiplas possibilidades, associados ao saber dar aula, ser artífice, junto com os alunos, de estratégias que favoreçam uma aprendizagem significativa); 6) os relacionados com a avaliação da aprendizagem, referentes à capacidade de saber retomar a trajetória percorrida, os objetivos previstos e as estratégias avaliativas que melhor informem sobre a aprendizagem dos alunos.

\section{Competências necessárias à docência}

Finalmente, fecham este estudo, as classificações e tipologias sobre os saberes da docência, realizadas desde a perspectiva das competências. Este terceiro grupo está integrado pelos trabalhos de Masetto (1998), Braslavsky (1999), Perrenoud (2000) e Zabalza (2006). No Brasil, o termo "competência" popularizou-se bastante, a partir da década de 1990, em todas as áreas da formação humana. Na educação, sua maior divulgação teve lugar por intermédio dos trabalhos de Perrenoud.

Excetuando os trabalhos de Masetto, os textos dos demais autores que compõem esta família de classificações manifestam uma clara preocupação em definir o que entendem por competência. Braslavsky (1999, p. 13) conceitua o termo "competência" sobre a docência como "a capacidade de fazer com saber e com consciência sobre as conseqüências desse saber. Toda competência envolve, ao mesmo tempo, conhecimentos, modos de fazer, valores e responsabilidades pelos resultados de aquilo que foi feito". Perrenoud (2000, p. 15), por sua vez, compreende "competência" no sentido de "capacidade de mobilizar diversos recursos cognitivos para enfrentar um tipo de situações". Finalmente, Zabalza 
(2006, p. 70) define "competência" como o "construto molar que nos serve para nos referirmos ao conjunto de conhecimentos e habilidades que os sujeitos necessitam para desenvolver algum tipo de atividade".

Masetto tornou-se um dos principais especialistas em questões de formação pedagógica de professores do ensino superior no Brasil. Autor de numerosas obras, é no final da década de 1990 que propõe uma tipologia própria das competências pedagógicas para a profissionalização da docência, primeira de seu tipo no Brasil sobre e para os professores do ensino superior. Segundo Masetto (1998), são três a competências específicas da docência no 3..$^{\circ}$ grau: 1) competência em uma área especifica (em uma determinada área de conhecimento), referente a um domínio dos conhecimentos considerados básicos (cognitivo), conhecimentos e práticas profissionais atualizados e domínio em uma área específica de conhecimento pela pesquisa; 2) competência na área pedagógica, relacionado com o conhecimento do próprio conceito de processo de ensino-aprendizagem, dos processos de concepção e gestão do currículo, ao conhecimento dos princípios relacionados com a relação professor-aluno e aluno-aluno no processo de aprendizagem, e domínio da teoria e da prática básica da tecnologia da educação; 3 ) competência na área política (capacidade para o exercício da dimensão política), associada à figura do professor como cidadão e como alguém comprometido com seu tempo, sua civilização e sua comunidade.

Já Braslavsky (1999), no contexto de um estudo sobre as Bases, orientaciones e criterios para el diseño de programas de formación de profesores [Bases, orientações e critérios para o planejamento de programas de formação de professores], se faz a seguinte pergunta: quais competências básicas deve ter um professor para poder conduzir férteis processos de ensino-aprendizagem no século XXI? Logo, dá a conhecer uma proposta de cinco competências necessárias ao novo perfil que deverão ter os professores que desempenham a docência na América Latina. A saber: 1) pedagógico-didática, referente à capacidade de conhecer, saber selecionar, utilizar, avaliar, aperfeiçoar e recriar ou criar estratégias de intervenção didáticas efetivas; 2) institucional, capacidade de articulação entre a macropolítica do sistema educativo e a micropolítica da escola e da sala de aula; 3) produtiva, capacidade para intervir no mundo de hoje e do futuro; 4) interativa, vinculada à capacidade de aprender a compreender e sentir com o outro; 5) especificadora, relacionada com a capacidade para abrir-se ao trabalho interdisciplinar, para aplicar um conjunto de conhecimentos fundamentais à compreensão de um tipo de sujeito, de uma instituição educativa, e/ou de um conjunto de fenômenos e processos.

Perrenoud (2000), por sua vez, manifesta clara preocupação pelos estudos sobre formação de professores, vinculados ao trabalho escolar, às práticas peda- 
gógicas e à inovação. Na obra em questão, busca-se abordar o ofício de professor de modo concreto, propondo um inventário das competências que contribuem para re-delinear a atividade docente. Como guia, Perrenoud toma um referencial de competências, adotado em Genebra em 1996, para a formação contínua, de cuja elaboração tinha participado ativamente. As competências selecionadas pelo autor são re-agrupadas em 10 (dez) grandes famílias. Segundo o próprio autor, as competências por ele formuladas não descrevem o professor médio de hoje, mas o perfil futuro desejável de profissional da docência. A classificação elaborada é a seguinte: 1) organizar e dirigir situações de aprendizagem; 2) administrar a progressão das aprendizagens; 3) conceber e fazer evoluir os dispositivos de diferenciação; 4) envolver os alunos em suas aprendizagens e em seu trabalho; 5) trabalhar em equipe; 6) participar da administração da escola; 7) informar e envolver os pais; 8) utilizar novas tecnologias; 9) enfrentar os deveres e os dilemas éticos da profissão; 10) administrar sua própria formação contínua.

A classificação e a tipologia das competências profissionais do docente universitário, elaboradas por Zabalza (2006) (ainda sem tradução para o português) e por Masetto (1998), são as únicas de seu tipo que abordam e discutem as competências profissionais dos professores que exercem a docência no âmbito do ensino superior. Essa talvez seja sua principal distinção. Ao mesmo tempo é, de longe, junto com a classificação de Perrenoud, a mais ampla e completa de todas as classificações localizadas e analisadas sobre os saberes associados à profissionalização dos professores.

A partir de um conjunto de definições diferentes sobre as competências e de um marco de referência conceitual mais amplo sobre as mesmas, Zabalza (2006) formula a si próprio duas interrogações: que poderia ser dito a respeito das competências da profissão docente? Que capacidades, no sentido mencionado, de conhecimentos e destrezas, caracterizam o trabalho que é levado a cabo pelos docentes universitários? As respostas levam o autor a analisar a figura e a função dos docentes universitários a partir de uma classificação e tipologia constituída por dez competências diferentes, a saber: 1) planejar o processo de ensino-aprendizagem ( $\mathrm{O}$ que se faz quando se planeja? Como planejam os professores? O que se planeja?); 2) selecionar e preparar os conteúdos disciplinares, relacionada com a capacidade de transformar o conhecimento científico em conhecimento capaz de ser ensinado e aprendido; 3) oferecer informações e explicações compreensíveis e bem organizadas (competência comunicativa), vinculada à produção comunicativa, ao reforço da compreensibilidade, à organização interna das mensagens e à conotação afetiva das mensagens; 4) manejo das novas tecnologias, associada ao domínio das novas tecnologias como objeto de estudo, como recurso didático, e como meio de expressão e comunicação; 5) conceber a metodologia e organizar as atividades, aliadas à organização dos 
espaços de aprendizagem, a seleção dos métodos, e seleção e desenvolvimento das tarefas instrutivas; 6) comunicar-se e relacionar-se com os alunos, referente à competência para trabalhar com classes numerosas, construir um estilo de liderança e um clima favorável na sala de aula; 7) tutoria, vinculado aos diversos tipos de tutorias, às funções do tutor universitário, aos dilemas da tutoria universitária, às condições do exercício da tutoria e à tutoria como empenho pessoal dos docentes universitários; 8) Avaliar, associada à necessidade de saber avaliar para o professor assumir seu papel facilitador e guia do aluno em seu processo de aprendizagem. Em tal sentido, o professor precisa conhecer a natureza e o sentido da avaliação na universidade, os componentes da avaliação (dados, valorações e decisões), o processo de planejamento, execução, avaliação e ajuste da avaliação etc.; 9) refletir e pesquisar sobre o ensino, associada à capacidade para analisar, documentadamente, o processo de ensino-aprendizagem desenvolvido (refletir) e submeter a análises controladas os distintos fatores que afetam a didática universitária em cada um dos âmbitos científicos (pesquisa) e apresentar dossiê e relatórios sobre as diversas questões relacionadas com o ensino universitário (publicar); 10) identificar-se com a instituição e trabalhar em equipe, trata-se de uma competência transversal no sentido de como todas as competências anteriores são afetadas pela integração dos professores na organização ou instituição e pela disposição (atitude) e atitude (técnica) para trabalhar coordenadamente com os colegas. Isto é, saber e querer trabalhar juntos num contexto institucional determinado.

\section{Considerações finais}

É abundante e importante a produção de classificações e tipologias que têm procurado ordenar a pluralidade, composição, temporalidade e heterogeneidade dos saberes, dos conhecimentos e das competências profissionais dos professores na América do Norte, na Europa e na América Latina, nestes últimos vinte anos. Ainda assim, e apesar de todas elas expressarem uma clara preocupação pela melhoria do ensino, da docência e de seus saberes, apresentam resultados que têm contribuído muito pouco no sentido de ajudar na compreensão que os próprios formadores de professores têm deste objeto de estudo. Parece que, na mesma medida que aumentam as pesquisas sobre o tema, mais complexas e menos inteligíveis elas se tornam.

As classificações e as tipologias analisadas dão uma ideia da diversidade de enfoques conceituais e metodológicos que sustentam as pesquisas educacio- 
nais das quais fazem parte. Elas são tão plurais, diversas e heterogêneas quanto seu próprio objeto de análise, o que faz com que seja quase impossível um estudo comparativo entre as mesmas. Ainda assim, foi possível agrupar as classificações e as tipologias selecionadas em três famílias diferentes: 1) as que utilizavam o termo "saberes" para fazer referência ao conjunto de capacidades necessárias à profissionalização da docência; 2) as que usavam o termo "conhecimento"; 3 ) as que empregavam o termo "competências". Com certeza, outros critérios de agrupamento poderiam ser estabelecidos, por exemplo, a partir das regiões geográficas e políticas (1-América do Norte; 2- Europa; 3- América Latina) ou por décadas.

Na educação, particularmente no ensino, os conceitos de "saberes", "conhecimentos" e "competências" têm, muitas vezes, sentidos diferentes e um é complemento do outro e vice-versa. Aqui não. Independentemente do agrupamento feito das classificações e tipologias para uma melhor análise, foi possível perceber que o significado conceitual dos termos empregados, para referir-se ao conjunto de capacidades mais ou menos sistematizadas necessárias para pôr em prática a profissão de professor ("conhecimento", "saberes" e "competências"), é quase o mesmo nos onze autores consultados. Para todos eles, a profissionalização da docência compõe-se de três ingredientes fundamentais, mas não suficientes: de saber, de saber-fazer e de saber-ser, apresentados na forma de saberes, de conhecimentos ou de competências.

\section{REFERÊNCIAS}

ALMEIDA, P. C. A. de; BIAJONE, J. A formação inicial dos professores em face dos saberes docentes. GT-8: Formação de Professores. 28. ${ }^{a}$ Reunião Anual da ANPEd. Realizada em 16 a 19 out. 2005. Caxambu-MG. Disponível em: <www.anped.org. br/28/textos $>$. Acesso em: 17/10/2006.

BITTAR, M. Pesquisa sobre formação de professores no Brasil e a Pós-graduação em Educação. In: Pesquisa e Docência: perspectivas e desafios à educação contemporânea. Caderno de Resumos. 3. Encontro de Pesquisa em Educação, Uberaba, p. 18.

BORGES, C. Saberes docentes: diferentes tipologias e classificações de um campo de pesquisa. Educação \& Sociedade, Campinas, v. 22, n. 74, abr. 2001.

BRASLAVSKY, C. Bases, orientaciones y criterios para el diseño de programas de formación de profesores. Revista Iberoamericana de Educación, n. 19, p. 1-28, 1999. 
BRZEZINSKI, I.; GARRIDO, E. Análise dos trabalhos do GT Formação de Professores: o que revelam as pesquisas do período 1992-1998. Revista Brasileira de Educação, São Paulo, n. 18, p. 82-100, set-dez. 2001.

CUNHA, M. I. da. A docência como ação complexa: o papel da didática na formação de professores. In: ROMANOWSKI, J. P.; MARTINS, P. L. O.; JUNQUEIRA, S. R. A. Conhecimento local e conhecimento universal: pesquisa, didática e ação docente. Curitiba: Champagnat, 2004. p. 31-42.

FREIRE, P. Pedagogia da autonomia. Saberes necessários à prática educativa. 15. ed. São Paulo: Editora Paz e Terra, 2000. (primeira edição em 1996).

GARCÍA, C. M. Como conocen los profesores la materia que enseñan: algunas contribuciones de la investigación sobre conocimiento didáctico del contenido. Ponencia presentada al Congreso Las didácticas específicas en la formación del profesorado, Santiago de Compostela, España, 6-10 jul. 1992. Disponível em: <www.prometeo. us.es/mie/pub/marcelo>. Acesso em: 17/10/2006.

GAUTHIER, C. Por uma teoria da Pedagogia. Pesquisas contemporâneas sobre o saber docente. Ijuí-RS: Editora INIJUI, 1998.

MASETTO, M. T. Professor universitário: um profissional da educação na atividade docente. In: . (Org.). Docência na universidade. Campinas-SP: Papirus, 1998. p. 926.

NUNES, C. M. F. Saberes docentes e formação de professores: um breve panorama da pesquisa brasileira. Educação \& Sociedade, ano XXII, n. 74, p. 27-42, abr. 2001.

PERRENOUD, Ph. 10 novas competências para ensinar. Porto Alegre: ArtMed, 2000 .

PIMENTA, S. G. Formação de professores: saberes da docência e identidade do professor. In: FAZENDA, I. (Org.). Didática e interdisciplinaridade. Campinas-SP: Editora Papirus, 1998. p. 161-178.

PIMENTA, S. G.; ANASTASIOU, L. das G. C. Docência no ensino superior. São Paulo: Cortez Editora, 2002.

PUENTES, R. V. Formação, Identidade e Profissionalidade do professor da Educação Básica e do Ensino Superior no contexto Ibero-americano: um estado da arte (19932005). Trabalho apresentado como parte da Mesa Redonda intitulada Formação, identidade e profissionalização do professor de educação básica e do ensino superior, no Seminário Universidade, Educação Escolar e Formação de Professores, realizado em Cuiabá, Mato Grosso, de 20 a 23 nov. 2005. 
SHULMAN, L. S. Conocimiento y enseñanza: fundamentos de la nueva reforma. Profesorado. Revista de Currículum y formación del profesorado, 9, 2, p. 1-30, 2005. Disponível em: <http://www.ugr.es/ recfpro/Rev92.html>. Acesso em: 17/10/2006.

. Knowledge and Teaching: Foundations of the New Reform. Harvard Educational Review, 57 (I), p. 1-22, 1987.

. Those Who Undertand: Knowledge Growth in Teaching. Educational Researcher, v. 15, n. 2, p. 4-14.

TARDIF, M. Saberes docentes e formação profissional. 3. ed. Petrópolis-RJ: Editora Vozes, 2003.

- Saberes profissionais dos professores e conhecimentos universitários. Elementos para uma epistemologia da prática profissional dos professores e suas conseqüências em relação à formação para o magistério. Revista Brasileira de Educação, n. 13, p. 5-24, jan./fev./mar./abr., 2000.

TARDIF, M.; LESSARD, C.; LAHAYE, L. Esboço de uma problemática do saber docente. Teoria \& Educação, v. 1, n. 4, p. 215-253, 1991.

TARDIF, M.; RAYMOND, D. Saberes, tempo e aprendizagem do trabalho no magistério. Educação \& Sociedade, Campinas, v. 21, n. 73, 2000. Disponível em: $<$ http://www.scielo.br/scielo.php?script=sci_arttext\&pid=S0101-733020000004000 $13 \& \operatorname{lng}=$ pt\&nrm=isso $>$. Acesso em: 21/11/ 2006.

ZABALZA, M. A. Competencias docentes del profesorado universitario. Calidad y desarrollo profesional. Madrid-Es.: Editora Narcea, 2006, 253p. 